\title{
Polymorphisms in Glutathione S-Transferase M1, T1, and P1 in Patients with Chronic Periodontitis: A Pilot Study
}

\author{
Victor Raul Camargo Ortega, ${ }^{1}$ Leliette Deyanira Bravo López, ${ }^{1}$ Angel Visoso Salgado, ${ }^{1}$ \\ Fernando Mejia Sanchez, ${ }^{2}$ and Julieta Castillo Cadena ${ }^{2}$ \\ ${ }^{1}$ Center of Research and Advanced Studies in Dentistry (CIEAO), Autonomous University of the State of Mexico, \\ 50130 Toluca, MEX, Mexico \\ ${ }^{2}$ Medical Research Center (CICMED), Autonomous University of the State of Mexico, 50130 Toluca, MEX, Mexico \\ Correspondence should be addressed to Angel Visoso Salgado; avisosos@uaemex.mx
}

Received 25 August 2014; Revised 1 November 2014; Accepted 5 November 2014; Published 25 November 2014

Academic Editor: Carlos Marcelo da Silva Figueredo

Copyright (C) 2014 Victor Raul Camargo Ortega et al. This is an open access article distributed under the Creative Commons Attribution License, which permits unrestricted use, distribution, and reproduction in any medium, provided the original work is properly cited.

\begin{abstract}
Background. Although the direct cause of chronic periodontitis is bacterial infection, the progression of this disease depends on genetic and environmental factors, and smoking is a known risk factor in the development and severity of the disease. An individual's susceptibility may be influenced by polymorphisms in the glutathione S-transferase genes. These genes encode enzymes that metabolize xenobiotic compounds. The aim of this study was to determine the frequency of GSTM1, GSTT1, and GSTP1 polymorphisms in Mexicans with chronic periodontitis. Methods. 60 Mexicans with chronic periodontitis (30 smokers and 30 nonsmokers) were studied. A peripheral blood sample was taken for subsequent DNA extraction. The genetic material was PCR-amplified followed by restriction fragment length polymorphism with the aim of identifying GST polymorphisms. Results. Polymorphisms in the GSTT1 and GSTP1 genes were not significantly different between the smokers and nonsmokers. However, there were significant differences $(P=0.05)$ between groups in polymorphisms in the GSTM1 gene. The patients with chronic periodontitis have a higher frequency of null and mutant polymorphisms in GSTM1, GSTT1, and GSTP1 compared with historical data from a healthy Mexican population. Conclusions. The presence of these polymorphisms may be a risk factor for the development of chronic periodontitis.
\end{abstract}

\section{Introduction}

According to the World Health Organization, periodontal diseases are the second most prevalent oral cavity diseases, trailing only dental caries. The latest oral health report from the World Health Organization (April 2012) indicates that between 15 and $20 \%$ of the middle-aged adult population (3545 years) has periodontal disease [1].

Data from the Health Department of Mexico the $8.8 \%$ of Mexican population has chronic periodontitis. This is more common between subjects of 35 years and older where it is estimated that the frequency is of $22 \%$, stressing that the age being most affected by dependence of snuff is between 35 and 65 years $[2,3]$.

Chronic periodontitis is defined as the inflammation and destruction of the periodontal tissue and the alveolar bone supporting the teeth. This affects normal oral functions as mastication, speech, and facial aesthetics [1]. The progression and severity of the disease depend on complex interactions between several risk factors such as microorganisms, age, race, and immunological, environmental, and genetic factors [4].

Polymorphisms are monogenic mutations in which the substitution of a nitrogenous base with a different base pair occurs. They are considered normal variants within the population and may or may not lead to variations in phenotype [5]. Several studies have reported that different polymorphic genes are associated with risk of developing chronic periodontitis [6-11].

There have been previous studies examining such genetic changes in glutathione S-transferase genes such as GSTM1, GSTT1, and GSTP1, which are involved in the detoxification 
TABLE 1: Sequences of primers used for end-point PCR.

\begin{tabular}{|c|c|c|}
\hline Genes & Sequence & Amplicon \\
\hline \multirow{2}{*}{ GSTM1 } & F-5'-GTTGGGCTCAAATATACGGTGG-3' & \multirow{2}{*}{215 bp } \\
\hline & R-5'-GAACTCCCTGAAAAGCTAAAGC-3' & \\
\hline \multirow{2}{*}{ GSTT1 } & F-5'-TCACCGGATCATGGCCAGCA-3' & \multirow{2}{*}{$480 \mathrm{bp}$} \\
\hline & R-5' -TTCCTTACTGGTCСТCACATCTC-3' & \\
\hline \multirow{2}{*}{ CYP1A1 } & F-5'-GAACTGCCACTTCAGCTGTCT-3' & \multirow{2}{*}{$312 \mathrm{bp}$} \\
\hline & R-5'-CAGCTGCATTTGGAAGTGCTC-3' & \\
\hline \multirow{2}{*}{ GSTP1b } & F-5 ${ }^{\prime}$-ACCCCAGGGCTCTATGGGAA-3' & \multirow{2}{*}{$176 \mathrm{bp}$} \\
\hline & R-5'-TGAGGGCACAAGAAGCCCCT-3' & \\
\hline \multirow{2}{*}{ GSTP1c } & F-5'-TGGCAGCTGAAGTGGACAGGATT-3' & \multirow{2}{*}{$332 \mathrm{bp}$} \\
\hline & R-5'-ATGGCTCACACCTGTGTCCATCT-3' & \\
\hline
\end{tabular}

of polycyclic aromatic hydrocarbons such as epoxides and hydroxylated metabolites of benzo-a-pyrene derived from tobacco $[12,13]$. Some studies indicate that smoking habits and polymorphisms in GST genes are associated with different diseases, including chronic periodontitis [14-17].

However, it is unclear whether the effect of smoking on chronic periodontitis is influenced by genetic susceptibility. Therefore, the aim of this study was to determine the frequency of GSTM1, GSTT1, and GSTP1 polymorphisms in Mexican population of smokers and nonsmokers with chronic periodontitis.

\section{Material and Methods}

2.1. Study Population and Clinical Examination. In total, 60 Mexican subjects were recruited for the present study. All cases were patients diagnosed with chronic periodontitis, in clinics at the Faculty of Dentistry at the Autonomous University of the State of Mexico. Patients with chronic periodontitis were classified according to the definitions used in the National Survey of Addictions in Mexico such as smoking people who reported having smoked in the past year and nonsmoking individuals who reported not smoking for a period of at least one year [18]. Both groups accepted their participation in the study by signing an informed consent designed for this purpose. Demographics and smoking habits data were obtained using a self-reported questionnaire.

This study was approved by the Ethics Committee of the Center for Research and Advanced Studies in Dentistry of the Autonomous University of the State of Mexico.

2.2. Diagnosis of Periodontal Disease. The patients were diagnosed according to the criteria of IWC 1999 International Workshop for a Classification of Periodontal Diseases and Conditions. The clinical and physical measurements, including the evaluation of probing depth, bleeding on probing, tooth mobility, number of teeth present, accumulation of mineralized plaque, and signs of inflammation, were recorded in order to identify severity and extent of disease $[19,20]$.

2.3. DNA Extraction. A $3 \mathrm{~mL}$ sample of peripheral blood from each participant was drawn into a Vacutainer tube with heparin, which was kept refrigerated until processed. DNA extraction was performed using the Quick-gDNA MiniPrep Kit (Zymo Research Corporation, USA). The products were verified by horizontal electrophoresis in $1 \%$ agarose and stored at $-15^{\circ} \mathrm{C}$ until the amplification.

2.4. Genotyping of GSTM1 and GSTT1 Polymorphisms. Identification of polymorphisms of GSTM1 and GSTT1 was performed by multiplex PCR with CYP1A1 gene as control. The mixture had a final volume of $25 \mu \mathrm{L}$, containing $5 \mu \mathrm{L} 5 \mathrm{x}$ PCR buffer, $1.5 \mu \mathrm{L}$ of $25 \mathrm{mM} \mathrm{MgCl}_{2}, 1 \mu \mathrm{L} 50 \mu \mathrm{M}$ dNTP, $9.4 \mu \mathrm{L}$ of molecular biology grade $\mathrm{H}_{2} \mathrm{O}, 0.1 \mu \mathrm{L} 5 \mathrm{U} / \mu \mathrm{L}$ Taq Polymerase (Promega, Madison, WI, USA), $2 \mu \mathrm{L}$ of DNA template, and $1 \mu \mathrm{L}$ of primers CYP1A1-f, CYP1A1-r, GSTM1-f, GSTM1-r, GSTT1-f, and GSTT1-r, all primers had a concentration of $30 \mathrm{pm}$ (Table 1) [21]. PCR conditions for these amplifications were 5 minutes at $94^{\circ} \mathrm{C}$, denaturation 1 minute at $94^{\circ} \mathrm{C}$, alignment 1 minute at $59^{\circ} \mathrm{C}$, extension 1 minute at $72^{\circ} \mathrm{C}$, and a final elongation of 5 minutes at $72^{\circ} \mathrm{C}$, for 35 cycles. PCR products were verified by horizontal electrophoresis using $2 \%$ agarose.

The determination of the polymorphism of GSTT1 was based on the presence of a $480 \mathrm{bp}$ band, corresponding to wild GSTT1, while its absence denoted a null GSTT1. Similarly, for GSTM1, the presence of a $215 \mathrm{bp}$ band indicated wild GSTM1, while its absence implied null GSTM1. Finally, a 312 bp band, corresponding to CYP1A1, was always present and was employed as a PCR control gene (Figure 1).

2.5. Genotyping of GSTP1 Polymorphisms. Identification of GSTP1b (exon 5) and GSTP1c (exon 6) was carried out in two separate PCRs, one for each polymorphism, both with a final volume of $25 \mu \mathrm{L}$ in order to obtain a sufficient amount of product for subsequent enzymatic digestions. The mixture for the PCR reaction contained $2 \mu \mathrm{L}$ of template DNA, $5 \mu \mathrm{L}$ of $5 x$ PCR buffer, $1.5 \mu \mathrm{L}$ of $25 \mathrm{mM} \mathrm{MgCl}_{2}, 0.1 \mu \mathrm{L}$ of $5 \mathrm{U} / \mu \mathrm{L}$ Taq Polymerase, $0.5 \mu \mathrm{L} 50 \mu \mathrm{M}$ dNTPs, $13.9 \mu \mathrm{L}$ molecular biology grade $\mathrm{H}_{2} \mathrm{O}$ (Promega, Madison, WI, USA), and $1 \mu \mathrm{L}$ of each primer according to the gene to be amplified: GSTP1b-f, GSTP1b-r, GSTP1c-f, or GSTP1c-r; all primers had a concentration of $30 \mathrm{pm}$ (Table 1) [22]. For GSTP1c PCR, the conditions were the same as those used for GSTT1 and GSTM1, while conditions for GSTP1b PCR were 5 minutes at 


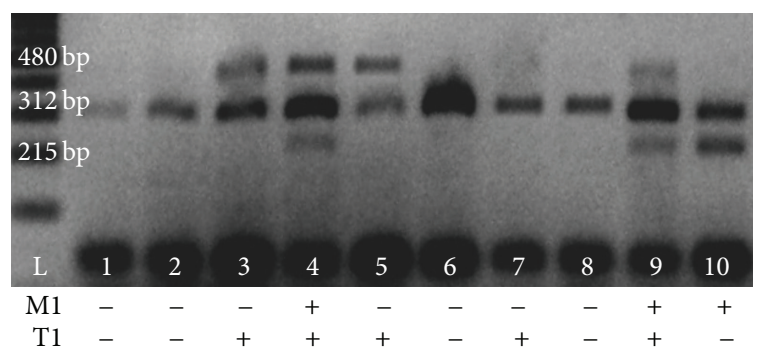

(a) Representative genotyping analysis of GSTM1 and GSTT1

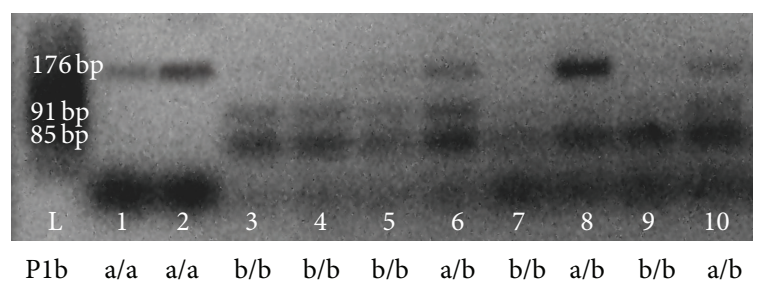

(b) Representative genotyping analysis of GSTP1b

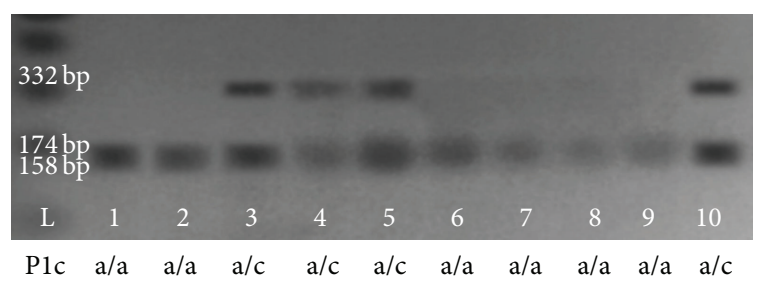

(c) Representative genotyping analysis of GSTP1c

Figure 1: Showing an example of 10 results obtained from the amplification of the GSTM1 and GSTT1 genes using the CP1A1 gene as a control. Additionally, gels showing the results of GSTP1b and GSTP1c detection.

$94^{\circ} \mathrm{C}$, denaturation 1 minute at $94^{\circ} \mathrm{C}$, alignment 1 minute at $62^{\circ} \mathrm{C}$, extension 1 minute at $72^{\circ} \mathrm{C}$, and a final elongation of 5 minutes at $72^{\circ} \mathrm{C}$ for a total of 35 cycles. For the identification of $\mathrm{P} 1$ polymorphisms, enzymatic digestions were carried out using BsmAI for P1b (exon 5) and AciI for P1c (exon 6). The digestion mixture consisted of $17 \mu \mathrm{L}$ molecular biology grade $\mathrm{H}_{2} \mathrm{O}, 2 \mu \mathrm{L}$ Fast-Digest Green buffer, $1 \mu \mathrm{L}$ Fast-Digest Enzyme (Fermentas), and $10 \mu \mathrm{L}$ PCR product DNA, for a total volume of $20 \mu \mathrm{L}$. Both digestion reactions were incubated at $37^{\circ} \mathrm{C}$ for 5 minutes.

The digestion products were verified by horizontal electrophoresis, using a $2 \%$ concentration of agarose. The identification of polymorphisms was based on the presence of DNA fragments of different sizes. For exon 5, $176 \mathrm{bp}, 91 \mathrm{bp}$, and $85 \mathrm{bp}$ fragments correspond to heterozygote $\mathrm{P} 1 \mathrm{~b}(\mathrm{a} / \mathrm{b})$ while $91 \mathrm{bp}$ and $85 \mathrm{bp}$ fragments correspond to homozygote $\mathrm{P} 1 \mathrm{~b}(\mathrm{~b} / \mathrm{b})$ and a $176 \mathrm{bp}$ fragment corresponds to wild type $\mathrm{P} 1 \mathrm{~b}(\mathrm{a} / \mathrm{a})$. Regarding exon 6 polymorphisms, the $332 \mathrm{bp}$ fragment corresponds to homozygote P1c (c/c); three fragments, $332 \mathrm{bp}, 174 \mathrm{bp}$, and $158 \mathrm{bp}$, correspond to heterozygote P1c (a/c) and two fragments, $158 \mathrm{bp}$ and $174 \mathrm{bp}$, correspond to wild type P1c (a/a) (Figure 1).

2.6. Statistical Analysis. To differentiate between the frequencies of each polymorphism the analysis performed was different
TABLE 2: Sociodemographic and disease characteristics of the study groups.

\begin{tabular}{|c|c|c|}
\hline & $\begin{array}{c}\text { Nonsmokers } \\
n=30\end{array}$ & $\begin{array}{c}\text { Smokers } \\
n=30\end{array}$ \\
\hline \multicolumn{3}{|l|}{ Age (years) } \\
\hline Mean \pm SD & $53.43 \pm 13.6$ & $44.43 \pm 7.39$ \\
\hline (interval) & $(25-72)$ & $(28-62)$ \\
\hline \multicolumn{3}{|l|}{ Gender (\%) } \\
\hline Male & $16(53.3)$ & $26(86.7)$ \\
\hline Female & $14(46.7)$ & $4(13.3)$ \\
\hline \multicolumn{3}{|l|}{ Education (\%) } \\
\hline Illiterate & $1(3.3)$ & $2(6.7)$ \\
\hline Elementary School & $12(40)$ & $10(33.3)$ \\
\hline High school & $9(30)$ & $5(16.7)$ \\
\hline College & $4(13.3)$ & $6(20)$ \\
\hline Professional & $4(13.3)$ & $7(23)$ \\
\hline \multicolumn{3}{|l|}{${ }^{\mathrm{a}}$ FMPS } \\
\hline Mean \pm SD & $54.20 \pm 17.68$ & $48.0 \pm 14.21$ \\
\hline (interval) & $(28-97)$ & $(26-80)$ \\
\hline \multicolumn{3}{|l|}{ Calculus } \\
\hline Mean \pm SD & $22.80 \pm 13.42$ & $20.67 \pm 7.19$ \\
\hline (interval) & $(4-68)$ & $(8-34)$ \\
\hline \multicolumn{3}{|l|}{ Teeth present } \\
\hline Mean \pm SD & $25.63 \pm 4.38$ & $23.83 \pm 4.19$ \\
\hline (interval) & $(13-31)$ & $(12-30)$ \\
\hline \multicolumn{3}{|l|}{ Disease severity (\%) } \\
\hline Mild & $11(36.7)$ & $12(40)$ \\
\hline Moderate & $14(46.7)$ & $14(46.7)$ \\
\hline Serious & $5(16.7)$ & $4(13.3)$ \\
\hline
\end{tabular}

${ }^{\mathrm{a}}$ Full mouth plaque score.

in proportions tested due to the nature of the variables. Statistical analysis was performed using SPSS software support in the 20 version (SPSS 20.0; SPSS Inc., Chicago, IL, USA).

\section{Results}

3.1. Study Population. The demographic and clinical characteristics of the subjects included in the study are presented in Table 2. The mean age of the nonsmokers was $53.43 \pm 13.6$ years, and the mean age of the smokers was $44.43 \pm 7.39$ years with a range of 25-72 years for all patients. With regard to the level of education, no differences were observed between the groups.

Regarding the characteristics of the disease found among smokers, there was an average loss of 1.8 more teeth compared to the nonsmokers. The results for the full mouth plaque score, calculus, and severity of the chronic periodontitis were very similar between groups.

3.2. Results of Polymorphisms of GSTM1, GSTT1, and GSTP1. The results of the analysis of polymorphisms in GSTM1 and GSTT1 indicated that there was a higher incidence of 
the GSTM1 null allele of $66.7 \%$ in the nonsmokers group compared to $43.4 \%$ with the GSTM1 null allele in the smokers group. Most individuals in both groups had the GSTT1 null polymorphism; the percentages were $73 \%$ of nonsmokers and $56.7 \%$ of smokers. The results of the identification of GSTP1 polymorphisms were very similar. It was observed that the GSTP1b a/a genotype was only present in the smokers group with an incidence of $10 \%$. No cases of the GSTP1c polymorphism were found in the homozygous form $\mathrm{c} / \mathrm{c}$ in both groups (Table 3 ).

When comparing the proportions of the polymorphisms between the smokers and the nonsmokers, no significant difference between the groups was observed for GSTT1 and GSTP1. No differences in the GSTM1 gene were expected; however, significant difference between the groups was observed for this polymorphism $(P \leq 0.05)$ (Table 3$)$.

As no differences between the groups were found in the majority of the genes studied, the patients with chronic periodontitis were grouped regardless of whether they smoked or not. With such grouping, the data obtained show that for both GSTM1 and GSTT1, there is a higher incidence of null polymorphisms. The results of the combined genotype analysis show that $80 \%$ of the patients have a null allele, that is, combinations $-/-,-/+,+/-$, with the double null genotype being the most frequent, representing $40 \%$ (Table 4 ). This condition is characterized by the absence of specific enzymatic activity and subsequent reduced ability to detoxify potentially toxic substances [16].

Similarly, when analyzing the total population with chronic periodontitis, the data indicate that for polymorphism GSTP1b, only $5 \%$ of patients have the a/a genotype, while the remaining $95 \%$ have some sort of variation. In contrast, $81.6 \%$ of patients had the a/a genotype for the GSTP1c polymorphism. No patients with the genotype c/c were reported (Table 4 ).

\section{Discussion}

The analysis of gene-environment interactions may be the best way to understand the increased susceptibility to chronic periodontitis. Inflammation is known to be a consequence of periodontal bacteria and harmful products derived from cigarette smoke. Additionally, GST is involved in the detoxification of toxins that cause oxidative stress; some studies suggest an association between chronic periodontitis and polymorphisms in genes encoding enzymes that metabolize compounds derived from tobacco smoke $[7,16,17]$.

Several authors have reported that smoking is a risk factor for periodontitis [23-27]. We compared patients who are smokers against those who are nonsmokers and found a very similar degree of disease severity between the groups. This result should be considered with caution because this study only examined the smoking habit during the last year, which gives the rise to considering some subjects who are recently quitters within the sample of nonsmokers. According to the literature, individuals with a lower education level are more likely to develop chronic periodontitis, which does not agree with this study $[1,4]$.
TABLE 3: Results of polymorphisms in GST M1, T1, P1b, and P1c of the study groups.

\begin{tabular}{ccc}
\hline Genotype & $\begin{array}{c}\text { Nonsmokers } \\
n=30(\%)\end{array}$ & $\begin{array}{c}\text { Smokers } \\
n=30(\%)\end{array}$ \\
\hline $\mathrm{M} 1$ & & \\
+ & ${ }^{\mathrm{b}} 10(33.3)$ & $17(56.7)$ \\
- & ${ }^{\mathrm{b}} 20(66.7)$ & $13(43.4)$ \\
$\mathrm{T} 1$ & & \\
+ & $8(26.7)$ & $13(43.4)$ \\
- & $22(73.3)$ & $17(56.7)$ \\
$\mathrm{P} 1 \mathrm{~b}$ & & $3(10)$ \\
$\mathrm{a} / \mathrm{a}$ & $0(0)$ & $15(50)$ \\
$\mathrm{a} / \mathrm{b}$ & $18(60)$ & $12(40)$ \\
$\mathrm{b} / \mathrm{b}$ & $12(40)$ & \\
$\mathrm{P} 1 \mathrm{c}$ & & $25(83.3)$ \\
$\mathrm{a} / \mathrm{a}$ & $24(80)$ & $5(16.7)$ \\
$\mathrm{a} / \mathrm{c}$ & $6(20)$ & $0(0)$ \\
$\mathrm{c} / \mathrm{c}$ & $0(0)$ &
\end{tabular}

TABLE 4: Results of polymorphisms in GST M1, T1, P1b, and P1c of patients with chronic periodontitis.

\begin{tabular}{cc}
\hline Genotype & $n=60(\%)$ \\
\hline $\mathrm{M} 1$ & \\
+ & $27(45)$ \\
- & $33(55)$ \\
$\mathrm{T} 1$ & \\
+ & $21(35)$ \\
- & $39(65)$ \\
$\mathrm{M} 1+\mathrm{T} 1$ & \\
$-/-$ & $24(40)$ \\
$-/+$ & $9(15)$ \\
$+/-$ & $15(25)$ \\
$+/+$ & $12(20)$ \\
$\mathrm{P} 1 \mathrm{~b}$ & \\
a/a & $3(5)$ \\
a/b & $33(55)$ \\
b/b & $24(40)$ \\
$\mathrm{P} 1 \mathrm{c}$ & \\
a/a & $49(81.6)$ \\
a/c & $11(18.4)$ \\
c/c & $0(0)$ \\
\hline
\end{tabular}

By combining the smoker and nonsmoker groups, we created a total sample of 60 Mexican subjects with chronic periodontitis. In this sample, $55 \%$ of patients had the GSTM1 null genotype, which is consistent with the data reported by Concolino et al. (2007). These authors found an increased presence of the GSTM1 null genotype in $73.9 \%$ of their study group comprising of Caucasians from central Italy with chronic periodontal disease, similar to our data. Both of these studies differ from studies in a Korean population conducted 
by Kim et al. (2004), who reported this allele in just $37 \%$ of their subjects. For the GSTT1 null genotype, our results showed a frequency of this allele in $65 \%$ in our patients, which differs from the Caucasian population data being $24.6 \%$ for this allele $[16,17]$.

Montero et al. (2007) performed a research study to determine the frequencies of polymorphisms in GSTM1 and GSTT1 in a healthy Mexican population with parents and grandparents born in Mexico. These authors had a study population comprising of 150 individuals, and they found that GSTM1 null is present with a frequency of $45 \%$ and that GSTT1 null has a frequency of $9.7 \%$. Pérez-Morales et al. (2008) performed a similar study comprising of 529 Mexicans, and these authors observed a frequency of $33.4 \%$ for GSTM1 null and 12\% for GSTT1 null [28, 29].

Comparing these data and our results using a population of 60 Mexicans with chronic periodontitis, an increase in the frequency of the GSTM1 null allele to $55 \%$ is observed and our data indicate that the GSTT1 null allele is present at a frequency of $65 \%$. Moreover, there is also an increase in the frequency of the combined GSTM1/T1 double null genotype, which was present in $40 \%$ of our patients compared to $2.2 \%$ and $4.24 \%$ reported by Pérez and Montero, respectively. This is consistent with the hypothesis that the double null combination leads to a decreased capacity to detoxify, which could lead to an increased susceptibility to chronic periodontal disease.

There are no data in any population showing the prevalence of GSTP1b and GSTP1c in relation to chronic periodontitis, but there are data on these genes in healthy populations. A study performed by Mejia et al. (2013) in 60 Mexican subjects reported frequencies for GSTP1b and GSTP1c polymorphisms. They reported that for the frequencies of the wild type P1b allele a/a was 33.3\%; the frequency of the heterozygous $\mathrm{P} 1 \mathrm{~b}$ allele $\mathrm{a} / \mathrm{b}$ was in $56.6 \%$, and the frequency of the homozygous P1b allele b/b was $10 \%$ [22].

Comparing both studies, we observed a decrease in the presence of the wild type allele a/a and an increase in the homozygous allele $b / b$ in our group of patients. Additionally, it is notable that $95 \%$ of the sick population of patients had some polymorphism in this gene. With regard to the distribution of GSTP1c, Mejia et al. reported that 100\% of the individuals in their study had the wild type genotype a/a [22], while in our study we found that $81.6 \%$ of patients were wild type a/a and $18.4 \%$ of patients were heterozygous a/c. This shows a decreased capacity to detoxify in patients with chronic periodontitis compared with historical data from a healthy population.

The observed frequencies of GSTM1 and GSTT1 nulls, GSTP1b and GSTP1c mutants show that these genes may confer increased susceptibility to chronic periodontal disease.

A better understanding of the function of the polymorphic genes GSTM1, GSTT1, and GSTP1 and a better understanding of the disease could contribute to the prevention of chronic periodontitis through personalized recommendations and specific intervention.

In conclusion, within the limitations of this study, the results suggest that compared with historical data from a healthy Mexican population, the population with chronic periodontitis shows an increase in null and mutant polymorphisms in GSTM1, GSTT1, and GSTP1. Therefore, the presence of these polymorphisms may be a risk factor for the presence of chronic periodontitis.

Importantly, the results of this pilot study comprise the first report of the presence of GSTM1, GSTT1, and GSTP1 polymorphisms in a Mexican population with chronic periodontitis. The future development of this research will be the realization of these tests in a larger group of patients to measure the relationship between susceptibility genes and chronic periodontitis.

\section{Conflict of Interests}

No potential conflict of interests relevant to this paper was reported.

\section{Acknowledgments}

The authors are grateful to dental practitioners who referred the patients to this project. This study was partially supported by the Autonomous University of the State of Mexico under the agreement 3452/2013 CHT.

\section{References}

[1] World Health Organization, "Oral health," Fact sheet no.318, 2012, http://www.who.int/mediacentre/factsheets/fs318/en/\#.

[2] SUIVE/DGE/SALUD, Morbidity Epidemiological Information, Yearbook 2011, executive version, SUIVE/DGE/SALUD, Mexico DF, Mexico, 2012.

[3] Department of Health, Results of epidemiological surveillance system of oral pathology SIVEPAB 2010, http://www.epidemiologia.salud.gob.mx/doctos/infoepid/bol_sivepab/SIVEPAB2010.pdf.

[4] J. M. Albandar, J. A. Brunelle, and A. Kingman, "Destructive periodontal disease in adults 30 years of age and older in the United States, 1988-1994," Journal of Periodontology, vol. 70, no. 1, pp. 13-29, 1999.

[5] M. L. Laine, B. G. Loos, and W. Crielaard, "Gene polymorphisms in chronic periodontitis," International Journal of Dentistry, vol. 3247, pp. 19-22, 2010.

[6] M. Ojima and T. Hanioka, "Destructive effects of smoking on molecular and genetic factors of periodontal disease," Tobacco Induced Diseases, vol. 8, no. 1, article 4, 2010.

[7] P. Meisel, R. Timm, H. Sawaf, J. Fanghänel, W. Siegmund, and T. Kocher, "Polymorphism of the N-acetyltransferase (NAT2), smoking and the potential risk of periodontal disease," Archives of Toxicology, vol. 74, no. 6, pp. 343-348, 2000.

[8] D. F. Kinane and T. C. Hart, "Genes and gene polymorphisms associated with periodontal disease," Critical Reviews in Oral Biology \& Medicine, vol. 14, no. 6, pp. 430-449, 2003.

[9] A. Droździk, M. Kurzawski, K. Safronow, and J. Banach, "Polymorphism in interleukin-lbeta gene and the risk of periodontitis in a Polish population," Advances in Medical Sciences, vol. 51, pp. 13-17, 2006.

[10] Y. Tachi, H. Shimpuku, Y. Nosaka et al., "Vitamin D receptor gene polymorphism is associated with chronic periodontitis," Life Sciences, vol. 73, no. 26, pp. 3313-3321, 2003. 
[11] S. Gunes, A. P. Sumer, G. C. Keles et al., "Analysis of vitamin $\mathrm{D}$ receptor gene polymorphisms in patients with chronic periodontitis," Indian Journal of Medical Research, vol. 127, no. 1, pp. 58-64, 2008.

[12] I. Borges Jr., E. A. Machado Moreira, D. W. Filho, T. B. de Oliveira, M. B. S. da Silva, and T. S. Fröde, "Proinflammatory and oxidative stress markers in patients with periodontal disease," Mediators of Inflammation, vol. 2007, Article ID 45794, 5 pages, 2007.

[13] D. L. Eaton and T. K. Bammler, "Concise review of the glutathione S-transferases and their significance to toxicology," Toxicological Sciences, vol. 49, no. 2, pp. 156-165, 1999.

[14] E. A. Miller, J. S. Pankow, R. C. Millikan et al., "GlutathioneS-transferase genotypes, smoking, and their association with markers of inflammation, hemostasis, and endothelial function: the atherosclerosis risk in communities (ARIC) study," Atherosclerosis, vol. 171, no. 2, pp. 265-272, 2003.

[15] J. Varghese, V. Bhat, G. Bhat, and N. Rao, "Evaluation of Glutathione-S-transferase and Ceruloplasmin levels in gingival crevicular fluid and gingival tissue as diagnostic markers for chronic periodontitis," Advances in Bioscience and Biotechnology, vol. 3, pp. 437-441, 2012.

[16] P. Concolino, F. Cecchetti, C. D'Autilia et al., "Association of periodontitis with GSTM1/GSTT1-null variants-a pilot study," Clinical Biochemistry, vol. 40, no. 13-14, pp. 939-945, 2007.

[17] J.-S. Kim, J. Y. Park, W.-Y. Chung, M.-A. Choi, K.-S. Cho, and K.-K. Park, "Polymorphisms in genes coding for enzymes metabolizing smoking-derived substances and the risk of periodontitis," Journal of Clinical Periodontology, vol. 31, no. 11, pp. 959-964, 2004.

[18] Department of Health, National Survey of Addictions 2011, M exico, 2012, http://www.conadic.salud.gob.mx/pdfs/ENA_2011_ TABACO.pdf.

[19] M. S. Tonetti and A. Mombelli, "Early-onset periodontitis," Annals of Periodontology, vol. 4, no. 1, pp. 39-53, 1999.

[20] G. C. Armitage, "Periodontal diagnoses and classification of periodontal diseases," Periodontology 2000, vol. 34, pp. 9-21, 2004.

[21] S. Z. Abdel-Rahman, R. A. El-Zein, W. A. Anwar, and W. W. $\mathrm{Au}$, "A multiplex PCR procedure for polymorphic analysis of GSTM1 and GSTT1 genes in population studies," Cancer Letters, vol. 107, no. 2, pp. 229-233, 1996.

[22] F. Mejia, J. Castillo, and J. Sanchez, "Development and application in Mexican of a method for the identification of polymorphisms of GSTP1," Journal of Medicine and Medical Sciences, vol. 4, pp. 287-290, 2013.

[23] A. Sham, L. Cheung, L. Jin, and E. Corbet, "The effects of tobacco use on oral health," Hong Kong Medical Journal, vol. 9, no. 4, pp. 271-277, 2003.

[24] S. J. Arbes, H. Ágústsdóttir, and G. D. Slade, "Environmental tobacco smoke and periodontal disease in the United States," American Journal of Public Health, vol. 91, no. 2, pp. 253-257, 2001.

[25] K. K. Hilgers and D. F. Kinane, "Smoking, periodontal disease and the role of the dental profession," International Journal of Dental Hygiene, vol. 2, no. 2, pp. 56-63, 2004.

[26] J. Zhou, B. L. Olson, and L. J. Windsor, "Nicotine increases the collagen-degrading ability of human gingival fibroblasts," Journal of Periodontal Research, vol. 42, no. 3, pp. 228-235, 2007.

[27] M. I. Ryder, "The influence of smoking on host responses in periodontal infections," Periodontology 2000, vol. 43, no. 1, pp. 267-277, 2007.
[28] R. Montero, A. Araujo, P. Carranza et al., "Genotype frequencies of polymorphic GSTM1, GSTT1, and cytochrome P450 CYP1A1 in Mexicans," Human Biology, vol. 79, no. 3, pp. 299-312, 2007.

[29] R. Pérez-Morales, C. Castro-Hernández, M. E. Gonsebatt, and J. Rubio, "Polymorphism of CYP1A1" $2 \mathrm{C}$, GSTM1" 0 , and GSTT1* 0 in a mexican mestizo population: a similitude analysis," Human Biology, vol. 80, no. 4, pp. 457-465, 2008. 


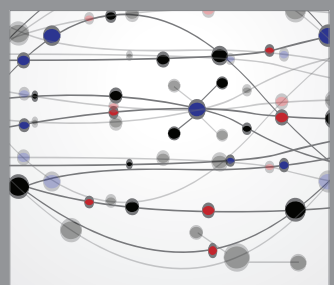

The Scientific World Journal
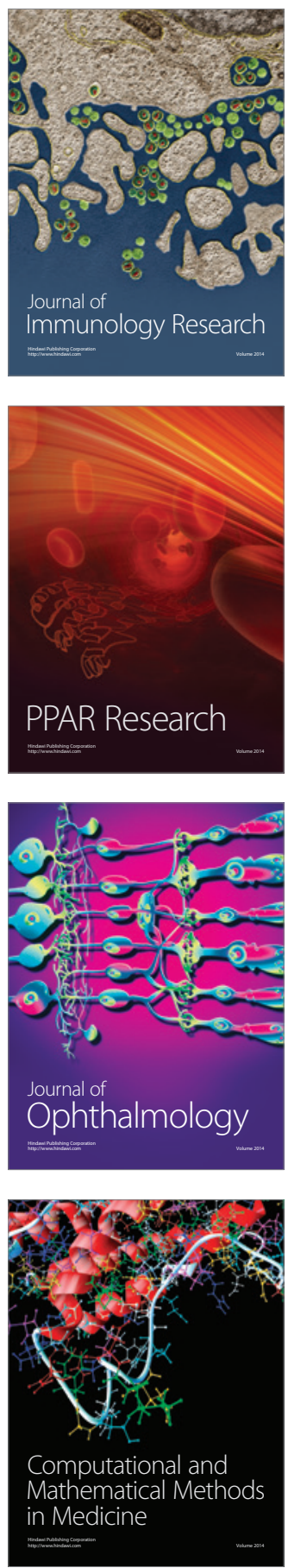

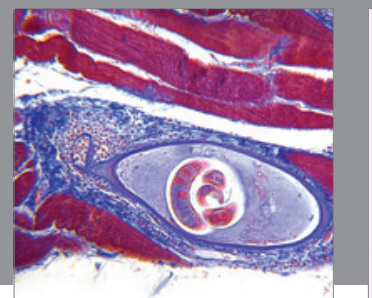

Gastroenterology

Research and Practice
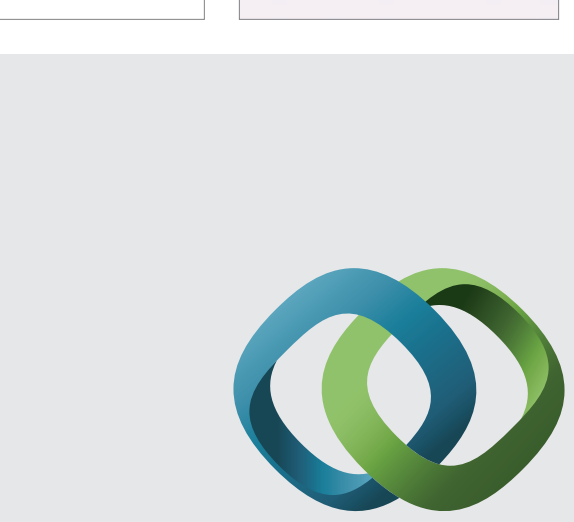

\section{Hindawi}

Submit your manuscripts at

http://www.hindawi.com
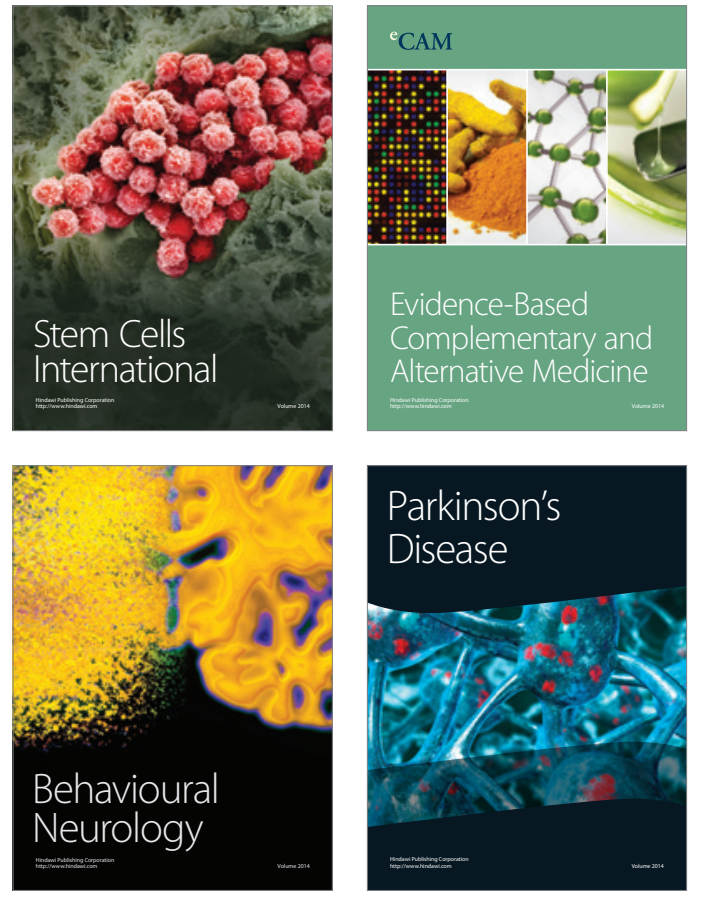
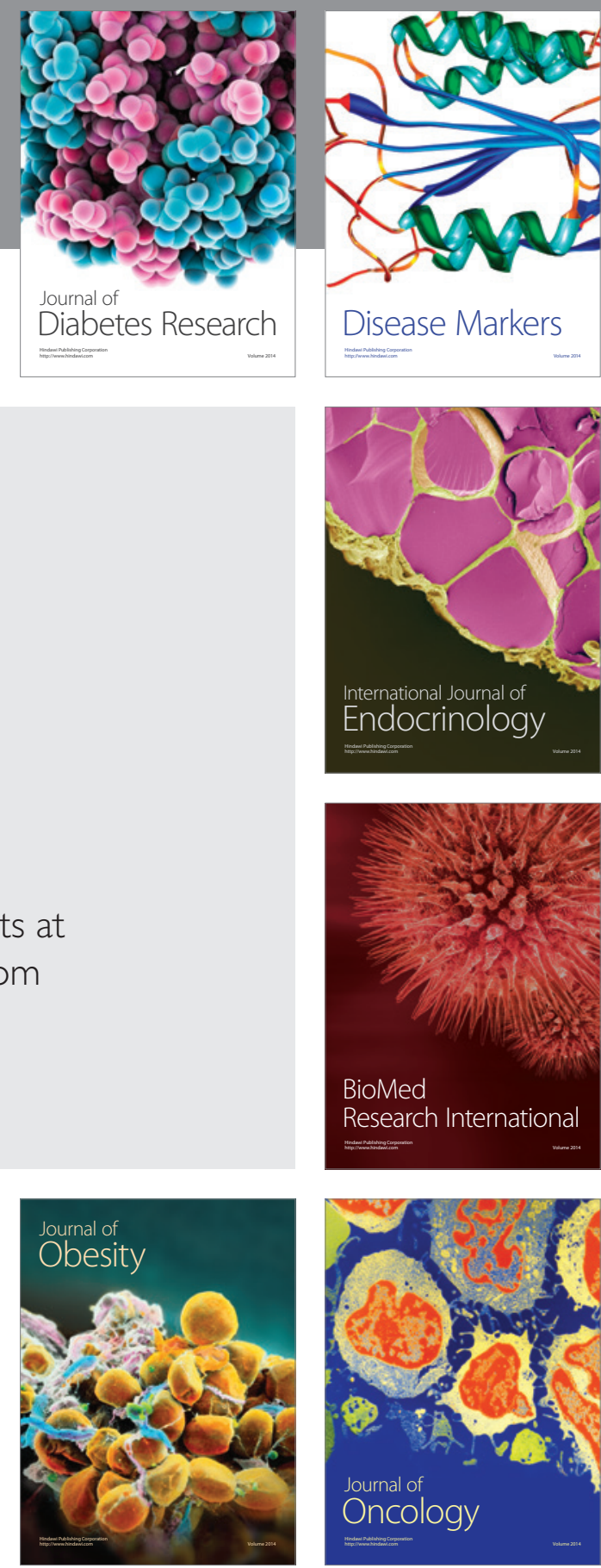

Disease Markers
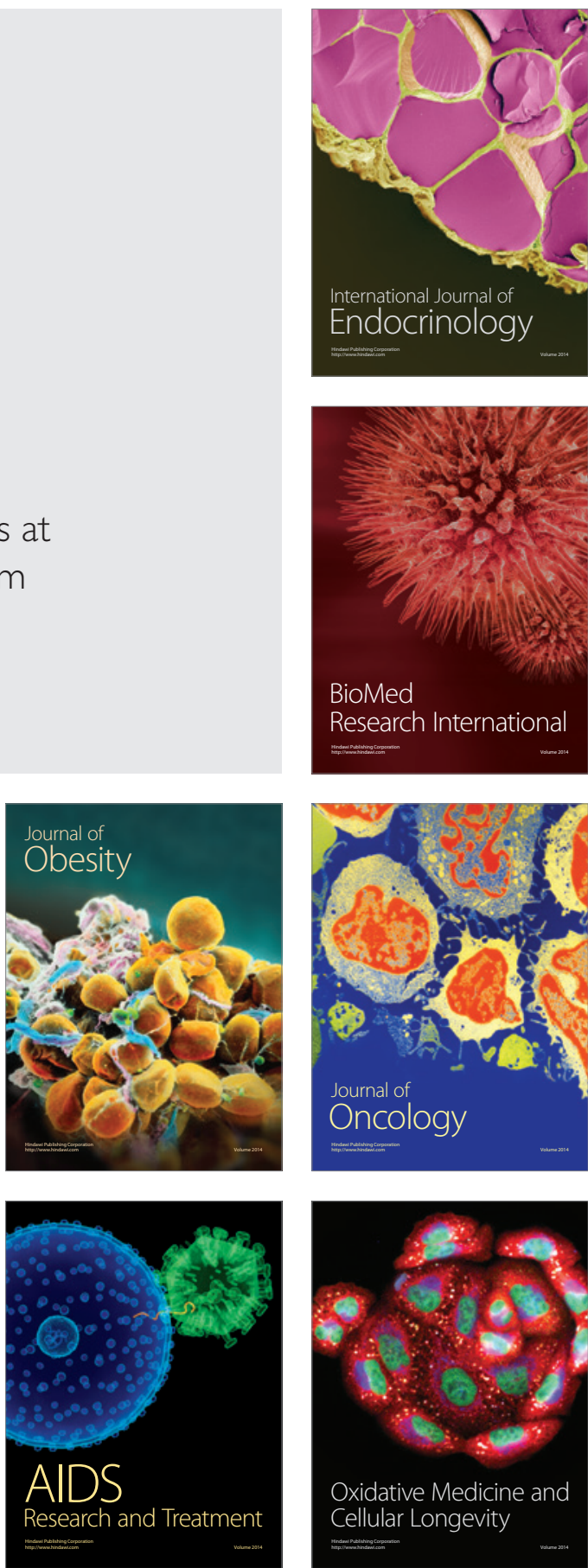